\title{
Optimization of Power Plant Generating Capacity Scheduling Based On Markov Model
}

\author{
Peng-Fei Liu ${ }^{1,2}$, Qun-tai Shen ${ }^{1}$ and Qiu-feng Chen $^{1}$ \\ ${ }^{1}$ School of Information Science and Engineering, Central South University, Changsha 410083, China \\ ${ }^{2}$ Unit 95856 of PLA, Nanjing 210028, China
}

\begin{abstract}
In this paper, we introduced the basic principles of energy saving generation dispatching, generated sorting table and implementation processes, implemented energy-saving generation dispatching optimal electric power industry structure and layout. From the terms of the pilot provinces, energy-saving generation dispatching pilots achieved remarkable results. The article proposed full process energy power scheduling of new concept which covered annual, monthly, recently and real-time full process of energy power scheduling. We established monthly plans range within optimization boot way and improved boot unit load rate through reasonable arrangements, and then designed annual, monthly, recently and real-time energy power scheduling plans. The article also researched coordination and convergence of power plans.
\end{abstract}

Keywords: Power plant, Generating capacity scheduling, Markov model, Power plan.

\section{INTRODUCTION}

Electric power industry is the priority areas of energy saving and pollution reduction, face enormous pressure of saving energy. The experts presented the first half of 2006, the State Council research office scheduling from the start implemented energy saving of electric power industry which will be a very effective way. This strategic plan spread, immediately available power is widely recognized in the industry. In 2006, the national development and Reform Commission led, the State electricity regulatory Commission, energy Office, the China electricity Council composed of several ministries and industry bodies joint investigation teams to 6 regional electricity markets nationwide and began scheduling reform research. Survey data shown that the energy saving regulation reform if implemented successfully, energy saving more than 100 million tons of standard coal annually, accounting for over $4 \%$ of China's total energy consumption for 2005 as a whole. The survey results show that by improving power scheduling method, in accordance with the principle of energy conservation, environmental protection, economic generation dispatching sequence, also has strong operability in reality which is the electric power industry "Eleven-Five" an important measure of energy saving targets [1]. For a long time, in an integrated management system of electric power industry coal consumption has been implemented in accordance with the levels sorted scheduling methods. But after 1985, with the rapid development of China's economy, growing gap between supply and demand of electricity, energy-saving schedule gradually became a dead letter. In order to solve the problem of power shortage as soon as possible, the State began to implement fund raising electricity in encouraging the construction of large, medium and small power plants [2]. In order to maintain the enthusiasm of parties to invest in building power stations and sharing interests, China has gradually changed the way electric power dispatching. Since then, the "indicator" becomes the core of power dispatch. In this scheduling rules, each generator power use hours a year is determined by the scheduling indicator $[3,4]$. Small thermal power units did not meet reserve generation plan targets, large units even though there is potential for more, while unfinished planned generating capacity of coal-fired units, are likely to leave the water for hydroelectric generating unit [5]. In General, the small unit of energy consumption rather than high pressure heater, power consumption is higher than that of electricity, but also impact on the environment than the latter $[6,7]$. But in fact the average distribution system indiscriminately encourages the development of small thermal power generating units, generating average coal consumption for power supply in the country remains high. Currently allocated average electricity power dispatching in the 80 's of last century has played a positive role, but under the current circumstances, such an approach cannot meet the need of energy saving and emission reduction [8].

Energy-efficient power generation scheduling is a scheduling change. It is also a major adjustment of electric power enterprise's profit distribution. Smooth transition from current generation dispatching methods to energy-saving generation dispatching, means not only needs to make the transition and perfect technical support, more important is to make the electric power enterprises economic benefit adjustment to achieve a smooth transition [9]. For this purpose, we need solve these problems, such as response to resource scarcity 


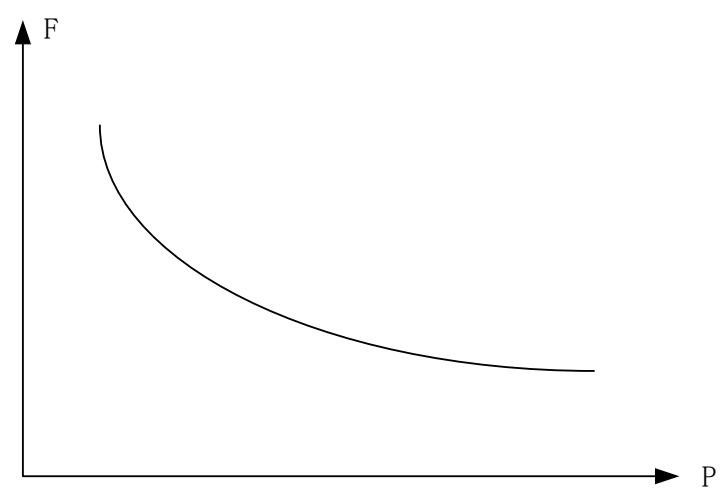

Fig. (1). Incremental changes with load.

and environmental costs of electricity pricing mechanism, and shutting down small thermal power plants with compensation and personnel problems after shutting down small power plant load power system security problems which is shown in Fig. (1).

Reform of the current mode of operation to carry out energy-saving generation dispatching is to reduce energy consumption and reduce pollutant emissions, promote the rapid and healthy development of the national economy which has a very important strategic position at the same time for the promotion of smaller units shutting down and adjust the structure of power. It also has great practical value [10].

\section{THEORY OF MARKOV MODEL}

Markov process is presented in 1906 by Markov and this generalization to accountably infinite state space is given by Ralph Cole Mo fruit in the year 1936. Markov chain is used for statistical modeling, bio-demographic modeling, and signal model focused on objects. We give below the basic concept of a Markov chain.

Actual process in the producer of observation results usually was description into signal. These signal may is discrete of, as letters table in the character and Telegraph password this in the quantitative of vector, while it also is continuous as voice sample and temperature of measure. These signal of signal source may is stable that statistics nature is not with time and change. These signals may be pure that it comes from just one source or it may be undermined by other signal sources such as distortion, reverb and so on.

Mathematical model for how to express and explain the real-world data is that people are very interested in the issue. There are many reasons people are interested in mode. Firstly, signal modeling for signal processing systems provide the basis for theoretical description so that the system can be used to process the data and get the desired results. For example, we expect to improve noise and speech signal transmission distortion damage, and then we can use the model to the design of a system. This system will be able to best remove noise and transmission distortion cancellation. Secondly, the signal can be used in cases where no signal source to help people understand the source of relevant knowledge which signals the actual process. Especially when the signal obtained from the actual signal source signal model is especially important when the high cost, because in this case the signal models we can build a good analog signal source and signal source by simulating as far as possible to learn more about knowledge. Finally, the signal model is one of the most important reasons that they are very good in practice and allow us to effectively achieve a number of important practical systems including the forecasting system, identification systems, identification systems, and so on.

$a_{i j}=P\left(\mathrm{X}_{n+1}=\mathrm{j} \mid X_{n}=i\right), \mathrm{A}=\left(\mathrm{a}_{i j}\right)_{i, j \leq t}$

$\mu_{i}=P\left(\mathrm{X}_{i}=i\right), 1 \leq i \leq L$

For the given nature of signal-signal model, it describes many of the possible and can be roughly divided into two categories: one is the deterministic models and another category is a statistical model. Deterministic models can be used to develop signal some of the known special properties for example sine wave or column index and so on. In such cases, signal model is very simple and only needs to determine or estimate the model parameters such as the sine wave of amplitude, frequency, phase, amplitude and frequency of the exponential function and so on. Type II model is a kind of statistical model describing statistical properties such as Gaussian processes and Poisson processes. Markov and hidden Markov processes is a type of statistical model. Statistical model implies an assumption: the signal can be well described as a stochastic process with parameters and parameters of the process can use a precise to definitive way to determine or estimate.

$$
P(Y \mid \lambda)=\sum_{i=1}^{L} a_{N}(\mathrm{i})
$$

Hidden Markov model has two article chain from $\mathrm{Yu}$ Markov chain which State chain is an article which cannot directly observation to Markov chain but can through addition an article observation chain observation to each moments of observation vector which is the moments by at state value of probability distribution performance. Each an observation vector is a corresponding probability density 
Table 1. Comparison of energy-saving generation dispatch and traditional dispatch.

\begin{tabular}{|c|c|c|}
\hline Way & Conventional & Energy-saving \\
\hline \hline Prerequisite & Safe and stable & Safe and stable \\
\hline Target & Safe & Energy saving \\
\hline Constraint & Security & Energy consumption \\
\hline Standard & Administrative economic & Optimal \\
\hline Principle & Equal & High efficiency \\
\hline Result & High pollution & \\
\hline
\end{tabular}

distribution of State sequence produced. Therefore, the hidden Markov model is a doubly stochastic process a certain number of hidden Markov chain and it shows a random set of functions. Hidden Markov models have been used successfully in many areas particularly with regard to recognition such as speech recognition, classification and so on.

\section{GENERATION DISPATCHING OPTIMAL METH- OD}

Measures for energy-saving generation dispatching of the trial process should be guided by the following basic principles. (1) Ensuring the safe and stable operation of power system and continuous electricity supply premise. (2) With energy-saving, environmental protection objectives. (3) All types of generator sets sorted by energy consumption and pollutant emission levels (4) provincial ranking optimization, interregional, intraregional coordination, implementation of optimal scheduling and power market construction give full play to role of the electricity market. (5) Try unit energy consumption and pollutant emissions in the production of electrical energy minimum. Comparison of energy-saving generation dispatch and traditional dispatch is shown in Table 1.

\subsection{Power Dispatch Mode}

This scheduling model to optimize the boot mode and improving level of energy-saving generation dispatching schedule inclusive ahead load forecast error with minimum energy consumption, proactive decision-making unit start-up mode, reducing the balance of supply and demand, peak demand in the future, the degree of risk of SCD. The main advantages are summarized below. (1) Improving energysaving generation dispatching the order. Coal-fired thermal power plants have greater physical inertia, which opened down processes involving slow dynamic processes of boiler heating system, start and stop procedure takes a long time to complete, and powering on after a period of time to achieve the best operational condition. Therefore press for energysaving generation dispatching in optimizing start-up mode for a longer time frame, optimizing decision-making unit contract completed, avoid frequent starting and stopping of unit, improved energy-saving generation dispatching the order. (2) Improving the efficiency of energy-saving generation dispatching. Measured units of consumption curves shows that coal consumption unit load-rate curves show a downward trend, namely as the load rate increase and reduce the coal consumption in power. Through a programmer of monthly boot optimization, ordered mediation between small units to achieve co-ordination between units of the same type, impressive run to unit load rate, reducing the system's total power consumption, improve the efficiency of energy-saving generation dispatching. (3) Improving the fairness of the energy-saving generation dispatching. Energy-saving generation dispatching an important aspect of fairness embodied in the sort of unit. Measured consumption and non-designed coal sort of out of touch with reality for incentives in operation of power generation enterprises to continue to employ a new technology, strengthening management, and reducing coal consumption, promoting energy-saving has positive significance and also improves the condition of energysaving generation dispatching fairness. Also, for identical or close coal-fired units of energy consumption and pollutant emission targets as phase I will sort according to promote power enterprises pay more attention to reducing pollutant emissions is significant.

\subsection{Generation Capacity Scheduling}

Annual power generation of the scheme includes the annual electricity output, generator maintenance scheduling arrangement, broken down by month and monthly of annual electricity power scroll coordination aspects.

(1) Determine the annual electricity generation. Annual power generation plan to carry the national energy development strategy, inter-regional, interprovincial programmer mid-term electric power transmission and sale of electricity to dissolve into consideration in the annual power generation plan. Meanwhile, for new energy saving and generation dispatch mode, the Government will no longer be given units of annual utilization hours. Annual electricity production of the unit will be based on the principle of energy-saving generation dispatching to determine objectively which will enhance the unit's utilization hours. Annual energy plan there are two types of presentation and they are based on historical data and to forecast economic trends analysis directly obtained electricity demand for the year. The second is the monthly forecast of electricity demand. It will get the annual cumulative month's electricity demand electricity demand. It is generally used in two ways to predict and compare adjustments and determine the optimal target annual electricity demand. 
(2) Arrangements for generator maintenance scheduling. Generator maintenance scheduling should be integrated into the annual planning of power generation in the context of assurance maintenance plan from the global scope of temporal and spatial equilibrium. The energy-saving generation dispatching measures provides that the generator maintenance consists of power generation enterprises in accordance with the relevant provisions of the regulations and apply to the actual needs and executed after approval by the corresponding power. Coal-fired and gas-fired generator maintenance should take advantage of annual electric. Electric power dispatching agencies at all levels should be based on load forecast and sort tables, on the premise of ensuring safe operation of the system, combination of factors and optimized generator set year, month, maintenance scheduling. Based on short-term load forecasting results scheduled equipment maintenance work.

(3) Annual quantity broken down by month. System of annual and monthly power determines according to system of power supply situation analysis and according to alternate rate of principles on unit of overhaul plans and various outside sale or into power plans for adjustment determines unit of annual each months run way according to each months of power needs according to energy power scheduling principles decomposition to each unit. Each unit each months power plans cumulative get unit annual power plans.

(4) The monthly quantity of rolling coordination. Power plant earlier this year will normally be submitted maintenance planning, scheduling its monthly contract agencies to coordinate arrangements. But the actual operation of thermal power units under the influence of many factors making its practical implementation of maintenance plan and may not be submitted at the beginning of the same. So when the monthly compilation of generation scheduling, it should first be changed according to the maintenance schedule monthly electricity target for amendments to the unit. If the units in this month's maintenance time increases, monthly charge reduced; if the repair time is reduced, then the monthly charge increases. Secondly, because load prediction error and future operation of the grid pattern of uncertainties and other factors, decomposition into monthly plan charge and the actual capacity of the unit there is a deviation, so we need to roll the unit's monthly electricity coordination to ensure the unit to complete the annual plan is generating. Therefore, in the rolling programmer of preparation, we should be completed taking into account complete months of actual monthly actual maximum power capacity, power and the future taking into account the change of the real plan back to roll the power breakdown and ensure balanced in order to meet the objectives of the annual energy generation dispatch request.

\section{POWER SCHEDULING MODEL}

Power optimization of an important goal is to pursue economic. Power optimization process should reflect the economy of various types of power supply costs include all the quantifiable costs occur in a row. With the implementation of fees based on total amount of pollutants in the environmental protection system in China, the original depreciation, maintenance and calculation of coal consumption by the unit cost of electricity and environmental costs as a means of cost or cost is calculated separately which has been unable to meet the requirements of economic analysis. Based on the above understanding, the paper first summarizes the current situation of China's power structure, systematically analyzes the characteristics of various types of power supply technology in the electric power industry as a whole, technology development, development, research and the world's advanced level of the domestic gaps and the reasons for these disparities. On this basis, according to the different roles of various types of power supply in the power grid, established majority power structure optimization model for regional power grid.

Current research focuses on power structure optimization in the new power type of capacity optimization, making new investments or planning period, total cost of the power supply. Traditional model without taking into account the sustainable development of resources of primary energy costs and environmental costs, is not conducive to existing power in the system to optimize the energy structure, thus making it impossible to minimize costs of the whole system, is not conducive to the realization of China's energy-saving generation dispatching. Power system is a unified of overall, and power load characteristics is with economic development level, changes of, original relative optimization of power structure himself cannot and changes of power load characteristics phase adapted, how in China sustainable development energy structure of guide Xia, full meet system of power needs and load characteristics requirements, will new power and original power combines up for unified planning, maximum to using mature of advanced technology and changes of energy structure situation combines up, The power structure is the optimal power system is an urgent need to address the problems in the energy saving and emission reduction. Power generation capacity and efficiency relationship is shown in Fig. (2).

\subsection{The Objective Function}

(1) Energy efficiency goals. We need to reduce our consumption of fossil fuels. From the perspective of reducing fossil fuel energy consumption, we gave power structure optimization model of energy consumption in the objective function.

$$
\min f_{c}=\min \sum_{i=1}^{m} \sum_{j=1}^{n}\left(F_{i, t-1}^{G_{j}}-F_{i, \mathrm{t}}^{G_{\bar{J}}}\right) f\left(G_{j}\right) h_{i, t}^{G_{j}}
$$

(2) Environmental targets. Emissions of pollutants once they are out, the management costs are very high, which we need to minimize the emissions of various pollutants. As the denomination of the various pollutants and environmental hazards are different, this pollutant treatment costs align measurement in the process of consumption of energy and emissions of various pollutants. For lowest cost of pollution as the goal, we gave the objective function of optimization model of the power structure in the environment. 


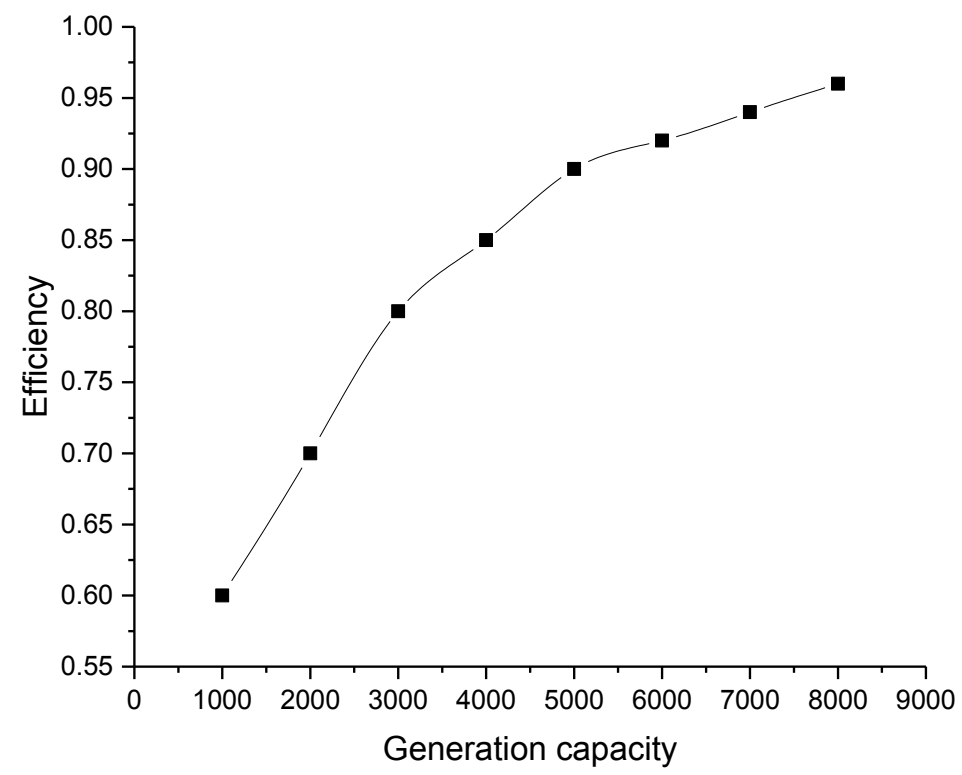

Fig. (2). Power generation capacity and efficiency relationship.

$\min f_{e}=\min \sum_{i=1}^{n} \sum_{k=1}^{N_{i}} \sum_{j=1}^{n_{i}}\left(\mathrm{~F}_{i, t-1}^{G_{j}}-\mathrm{F}_{i, t}^{G_{\bar{j}}}\right) h_{i, t}^{G_{j}} S_{i, k, \mathrm{j}}^{G_{j}}$

(3) Economic goals. Rising energy prices will have a negative impact on GDP. Higher energy prices would sooner or later by energy products to non-energy products, sustained higher energy prices may lead to inflation and an economic slowdown. In order to relieve tight energy supply's negative impact on the economy, with average tariff increases as low as possible for the target, we established the economic aspects of the objective function.

$\min \Delta p_{t}=\min \left(p_{t}-p_{t-1}\right)$

\subsection{Constraint Conditions}

Constraints described the energy, electricity and the interrelationships between the economy and the environment. Following analysis of relationship between the various goals of decision variables, we gave the corresponding constraint.

(1) Energy-saving constraints. With a view to reduce the consumption of fossil fuels and increase utilization of renewable energy, we promote power structure optimization adjustment units compared with the previous year under power generation fossil energy intensity which has fallen by at least a percentage stipulated by the Government.

$\frac{f_{c}^{t-1}-f_{c}^{t}}{f_{c}^{t-1}} \geq \eta_{t}^{\alpha}$

$\sum_{j=1}^{n_{t}} F_{i, t}^{G_{j}} \leq F_{i, \max }$

(2) The reduction constraints. In order to reduce pollutant emissions in power generation, we promote power structure optimization adjustment and set out the emission reduction targets for the units compared with the previous year percentage power generation discharges of pollutants to the Government regulations.

$\frac{f_{e}^{t-1}-f_{e}^{t}}{f_{e}^{t-1}} \geq \eta_{t}^{\beta}$

(3) Power supply and demand constraints.

$\sum b_{i, t}^{G_{j}} F_{i, t}^{G_{j}} \geq \sum F_{i, t}\left(1+r_{i}\right)$

(4) System reliability constraint.

$$
\begin{aligned}
& \text { LOLP }_{t} \leq L O L P_{t_{\text {max }}} \\
& \text { EENS }_{t} \leq E E N S_{t \text { max }}
\end{aligned}
$$

\section{ANALYSIS OF RESULTS}

Implementation of energy-saving generation dispatching is conducive to the implementation of the energy conservation and emission reduction target. It also helps speed up the power restructuring accelerated differentiation of power enterprises, promoting the development of renewable energy generators and large environmental protection units forcing high energy-consuming and highly polluting small coal-fired power generator and fuel to gradually withdraw from the market.

That will help accelerate China's power production capacity the fittest in promoting power optimization and upgrading of industrial structure as a whole produces boost. The entire industry will be a big adjustment. For hydro, wind, solar, Ocean, biomass, geothermal and other renewable energy generators with meeting the environmental 


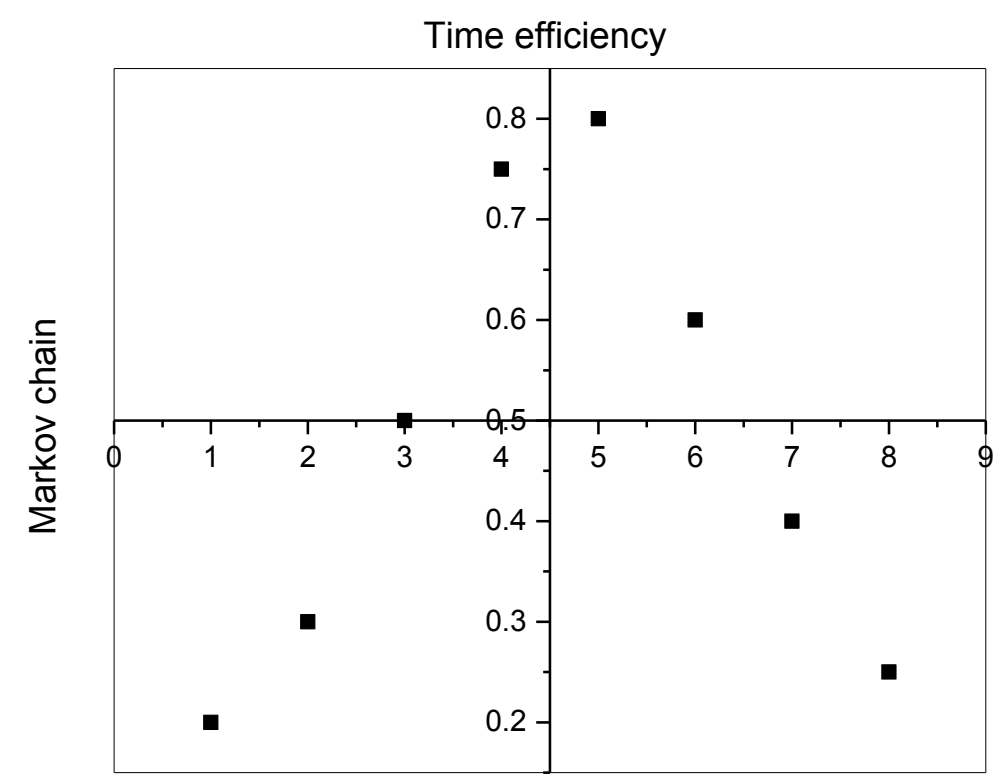

Fig. (3). Markov chain effects on efficiency of scheduled time.

requirements of the waste generators and nuclear power generators owned power generation enterprises is very advantageous for high energy consumption in medium and small coal-fired units would be very negative. Fig. (3) shows markov chain effects on efficiency of scheduled time.

In addition, the supply curve formed during the electricity trade doesn't consider the true cost of generating external environmental costs, thus achieving deals might have some gaps with energy saving and emission reduction targets. Therefore consideration discounts as a binding condition for energy saving and emission reduction targets or consider purchasing cost and energy-saving multiple-objective optimization. The other hand, because of the scheduling order has changed, energy-saving schedule will also have an impact on grid, shutting down small power plants need to compensate laid off workers in need of resettlement, less power needed to compensate for thermal power plant, power grid corporation needed to compensate the reactive power service provided. Energy saving dispatch mode, due to changes in the trend, if shutting down a load centers, small units, there may well be some section current overload to affect system security.

In the power market construction in a transitional period, we must take into account the external environmental costs of power generation enterprises, thereby bidding can be combined with energy conservation and emission reduction. In the current implementation of energy saving generation dispatching mode, we change the minimum cost of conventional power generation as the only goal in replacing them with energy-saving, environmental protection, economic targets in accordance with existing energy-saving generation dispatching practice arrangements for generating. Then we guide the investment direction of power supply to optimize the structure of power and energy-saving schedule and promote each other.
The article will carry out that energy-saving generation dispatching will bring some interest patterns to reallocate. Compensation for shutting down small power plants, power grid enterprises are interested in rising purchasing costs and providing ancillary services which would require compensation. Battery replacement benefit analysis provides the reference for interest compensation.

\section{CONFLICT OF INTEREST}

The authors confirm that this article content has no conflict of interest.

\section{ACKNOWLEDGEMENTS}

This work is supported by the National Natural Science Foundation of China (60974048)

\section{REFERENCES}

[1] E. Ni, B. L. Peter, and S. Rourke, "Optimal integrated generation bidding and scheduling with risk management under a deregulated power market," Power Systems, IEEE Transactions on, vol. 19, no. 1, pp. 600-609, 2004.

[2] D. K. Mohanta, P. K. Sadhu, and R. Chakrabarti, "Fuzzy Markov model for determination of fuzzy state probabilities of generating units including the effect of maintenance scheduling," Power Systems, IEEE Transactions on, vol. 20, no. 4, pp. 2117-2124, 2005.

[3] B. Roy, M. Fotuhi-Firuzabad, and B. Lina, "Bibliography on the application of probability methods in power system reliability evaluation 1996-1999," Power Systems, IEEE Transactions on, vol. 16, no. 4, pp. 595-602, 2001.

[4] A. Krogh, B. Larsson, G. Von Heijine, and E.L. Sonnhammer, "Predicting transmembrane protein topology with a hidden Markov model: application to complete genomes." Journal of Molecular Biology, vol. 305, no. 3, pp.567-580, 2001.

[5] E. L. Sonnhammer, G. Von Heijne, and K. Anders, "A hidden Markov model for predicting transmembrane helices in protein sequences," International Conference on Intelligent Systems for Molecular Biology, vol. 6, pp. 175-82, 1998. 
[6] D. K. Mohanta, P. K. Sadhu, and R. Chakrabarti, "Deterministic and stochastic approach for safety and reliability optimization of captive power plant maintenance scheduling using GA/SA-based hybrid techniques: A comparison of results," Reliability Engineering \& System Safety, vol. 92, no. 2, pp. 187-199, 2007.

[7] D. K. Mohanta, P. K. Sadhu, and R. Chakrabarti, "Fuzzy reliability evaluation of captive power plant maintenance scheduling incorporating uncertain forced outage rate and load representation," Electric Power Systems Research, vol. 72, no. 1, pp. 73-84, 2004.

[8] D. L. Yao, S.S. Choi, K.J. Tseng, and T.T. Lie, "Determination of short-term power dispatch schedule for a wind farm incorporated with dual-battery energy storage scheme." Sustainable Energy, IEEE Transactions on, vol. 3, no. 1, pp. 74-84, 2012.

[9] A. Mahor, and S. Rangnekar, "Short term generation scheduling of cascaded hydro electric system using novel self adaptive inertia weight PSO," International Journal of Electrical Power \& Energy Systems, vol. 34, no. 1, pp.1-9, 2012.

[10] M. Vrakopoulou, K. Margellos, J. Lygeros, and G. Anderson, "A probabilistic framework for security constrained reserve scheduling of networks with wind power generation, "In: Energy Conference and Exhibition (ENERGYCON), 2012 IEEE International. IEEE Florence, pp. 542-457, 2012.

Received: July 05, 2015

(C) Liu et al.; Licensee Bentham Open.

This is an open access article licensed under the terms of the Creative Commons Attribution Non-Commercial License (http://creativecommons.org/licenses/by$\mathrm{nc} / 3.0 /$ ) which permits unrestricted, non-commercial use, distribution and reproduction in any medium, provided the work is properly cited. 